\title{
Effect of Carbonate and Chloride Ions on the Corrosion Susceptibility of Pipeline Steel Samples Artificially Aged
}

\author{
Perla Morales Gil ${ }^{1, *}$, Manuel Palomar-Pardavé2, María Guadalupe Montes de Oca-Yemha ${ }^{2}$, \\ María Teresa Ramírez-Silva ${ }^{3}$, Carlos Ángeles-Chávez", Mario Romero-Romo ${ }^{2, *}$ \\ ${ }^{1}$ Instituto Mexicano del Petróleo, Laboratorio de Caracterización de Materiales Sintéticos y Naturales, \\ Eje Central Lázaro Cárdenas 152, Ciudad de México, CDMX. CP 07730 \\ ${ }^{2}$ Universidad Autónoma Metropolitana-Azcapotzalco, Departamento de Materiales, Av. San Pablo \\ 180 Col. Reynosa-Tamaulipas, Ciudad de México, CDMX. CP 02200 \\ ${ }^{3}$ Universidad Autónoma Metropolitana-Iztapalapa, Departamento de Química, Av. San Rafael Atlixco \\ \#186, Col. Vicentina, Ciudad de México, CDMX. CP 09340. \\ *E-mail: moralesp@imp.mx (P.M.G) and $\underline{\text { mmrr@ correo.azc.uam.mx (M.R.R.) }}$
}

doi: $10.20964 / 2018.02 .53$

Received: 2 October 2017 / Accepted: 30 November 2017 / Published: 28 December 2017

This work deals with the corrosion behavior of pipeline steel samples (API 5L X52 and X70), artificially aged through heat treatment, in the presence of aqueous solutions containing either carbonate $\mathrm{CO}_{3}{ }^{2-}$, or chloride $\mathrm{Cl}^{-}$anions, usually present during normal operating conditions. It was found from resistance to polarization measurements that $\mathrm{Cl}^{-}$ions were more aggressive toward the materials tested than $\mathrm{CO}_{3}{ }^{2-}$. Furthermore, from thermodynamic predominance zone diagrams, PZD, and SEM-EDS characterization of the surfaces exposed to the corrosion environment, it is shown that $\mathrm{Cl}^{-}$ions promoted formation of soluble $\mathrm{Fe}(\mathrm{II})$ chloro-complexes, which were the species produced during steel corrosion. These facilitated exposure of metal zones that had been first covered with corrosion products that formed under conditions of local chlorides-depletion, although now they had dissolved through the chloride interaction. This in fact eliminates the possibility of consolidating a passive layer. Conversely, when the $\mathrm{CO}_{3}{ }^{2-}$ are present, dissolution of passivating products like insoluble $\mathrm{Fe}(\mathrm{II})-\mathrm{CO}_{3}{ }^{2-}$ complexes is less likely to occur, thus aiding to diminish the corrosion rate.

Keywords: artificial ageing; steel; corrosion; carbonates; chlorides; predominance zone diagrams

\section{$\underline{\text { FULL TEXT }}$}

(C) 2018 The Authors. Published by ESG (www.electrochemsci.org). This article is an open access article distributed under the terms and conditions of the Creative Commons Attribution license (http://creativecommons.org/licenses/by/4.0/). 